\title{
¿A Comparison of Tropical Cyclone Projections in a High-Resolution Global Climate Model and from Downscaling by Statistical and Statistical-Deterministic Methods
}

\author{
Renzhi Jing, ${ }^{a}$ Ning Lin, ${ }^{a}$ Kerry Emanuel, ${ }^{\text {b }}$ Gabriel Vecchi, ${ }^{\mathrm{c}}$ And Thomas R. KNutson ${ }^{\mathrm{d}}$ \\ ${ }^{a}$ Department of Civil and Environmental Engineering, Princeton University, Princeton, New Jersey \\ ${ }^{\mathrm{b}}$ Department of Earth, Atmospheric and Planetary Sciences, Massachusetts Institute of Technology, Cambridge, Massachusetts \\ ${ }^{\mathrm{c}}$ Department of Geosciences, Princeton University, Princeton, New Jersey \\ d NOAA/Geophysical Fluid Dynamics Laboratory, Princeton, New Jersey
}

(Manuscript received 25 January 2021, in final form 6 August 2021)

\begin{abstract}
In this study, we investigate the response of tropical cyclones (TCs) to climate change by using the Princeton environment-dependent probabilistic tropical cyclone (PepC) model and a statistical-deterministic method to downscale TCs using environmental conditions obtained from the Geophysical Fluid Dynamics Laboratory (GFDL) High-Resolution Forecast-Oriented Low Ocean Resolution (HiFLOR) model, under the representative concentration pathway 4.5 (RCP4.5) emissions scenario for the North Atlantic Ocean basin. The downscaled TCs for the historical climate (1986-2005) are compared with those in the middle (2016-35) and late twenty-first century (2081-2100). The downscaled TCs are also compared with TCs explicitly simulated in HiFLOR. We show that, while significantly more storms are detected in HiFLOR toward the end of the twenty-first century, the statistical-deterministic model projects a moderate increase in TC frequency and PepC projects almost no increase in TC frequency. The changes in storm frequency in all three datasets are not significant in the mid-twenty-first century. All three project that storms will become more intense and the fraction of major hurricanes and category-5 storms will significantly increase in the future climates. However, HiFLOR projects the largest increase in intensity, and PepC projects the least. The results indicate that HiFLOR's TC projection is more sensitive to climate change effects and that statistical models are less sensitive. Nevertheless, in all three datasets, storm intensification and frequency increase lead to relatively small changes in TC threat as measured by the return level of landfall intensity under the projected climate condition.
\end{abstract}

SIGNIFICANCE STATEMENT: The study provides the first comparison among TC climatology projections based on statistical, statistical-deterministic, and dynamic models driven by the same environmental conditions. Under the projected climate for the RCP4.5 emissions scenario for North Atlantic, all three models project TC intensity to significantly increase, with the dynamic model HiFLOR projecting the largest increase in intensity. While HiFLOR projects a significant increase in TC frequency toward the end of the twenty-first century, the statistical-deterministic model projects a moderate increase in TC frequency, and the statistical model projects almost no increase in TC frequency. In all three datasets, storm intensification and frequency increase lead to relatively small changes in TC threat as measured by the return level of landfall intensity under the projected climate condition.

KEYWORDS: Climate change; Hurricanes/typhoons; General circulation models; Stochastic models

\section{Introduction}

Tropical cyclones (TCs) are among the most destructive natural hazards on Earth, and they have caused great economical and societal losses. Studies have shown that TCs may induce more damage under the impact of anthropogenic global warming (e.g., Mendelsohn et al. 2012). Although many studies have investigated how TCs will change in a changing climate, great uncertainties exist. The vast majority of published studies have suggested a decline in the global frequency of TCs with warming (e.g., IPCC 2013; Knutson et al. 2010; Walsh et al. 2016; Knutson et al. 2020), but a few others suggest an increase in TC frequency

\footnotetext{
¿ Denotes content that is immediately available upon publication as open access.
}

Corresponding author: Ning Lin, nlin@princeton.edu
(Emanuel 2013; Bhatia et al. 2018; Fedorov et al. 2018; Vecchi et al. 2019). In a recent assessment (Knutson et al. 2020) most of the assessment's authors conclude that there is a low-to-medium confidence in a future global reduction of TC frequency, although there is considerable divergence of opinion among the author team of the assessment. Also, Knutson et al. (2020) find that there is less agreement among modeling studies on the projected sign of change in Atlantic basin frequency than for the case for the global projections, although a clear majority of studies project a decrease for the Atlantic basin. Contrary to the divergent projections in TC frequency, a consensus has emerged about increased TC intensity as well as increased TC-induced rainfall rates (Knutson et al. 2020, 2013; Scoccimarro et al. 2014; Villarini and Vecchi 2012; Liu et al. 2019; Stansfield et al. 2020). Other storm-related hazards are also shown to become exacerbated under climate change. For example, Marsooli et al. (2019) suggest that hurricane flood hazards along the U.S. Atlantic and Gulf coasts are likely to significantly increase, due to storm 
changes as well as sea level rise. However, while there is high confidence that sea level rise will add to storm inundation levels, the extent to which TC intensity, rainfall, and storm-induced surge will increase remains quite uncertain (e.g., Knutson et al. 2020; Emanuel 2017; Marsooli et al. 2019; Garner et al. 2017). Improved assessment of climate change effects on TC and TCrelated hazards continues to be of great importance for both scientific understanding and climate adaptation practice.

Three main modeling approaches are used to investigate the response of TC climatology to climate change: general circulation models (GCMs), dynamic downscaling, and synthetic downscaling. The previous generation of global climate models is widely used for global projections; however, these models cannot directly simulate intense TCs due to their relatively low resolution (Davis 2018). The dynamic downscaling techniques that are usually paired with these low-resolution GCMs are alternative approaches to better resolve TCs. Pioneered by Knutson et al. (1998) and Knutson and Tuleya (2004), dynamic downscaling resolves the TC structure with an embedded higher-resolution regional model, which inherits the environmental conditions from GCMs (Knutson et al. 2013, 2015). Although effective in resolving individual storms, dynamic downscaling methods are still computationally expensive and thus not ideal for TC risk assessment studies, where large numbers of storms $\left(\sim 10^{4}\right)$ are often needed to evaluate the risk posed to a specific region (e.g., Lin and Emanuel 2016).

Recently a few GCMs have been able to explicitly simulate intense TCs. This eliminates the need for a separate dynamical downscaling step for the GCMs in climate change experiments (Wehner et al. 2014). These GCMs have grid spacings of $28 \mathrm{~km}$ or finer and can explicitly represent category-4 and category-5 TCs [e.g., the Centro Euro-Mediterraneo sui Cambiamenti Climatici Climate Model (CMCC-CM2-VHR) developed by Scoccimarro et al. (2017) and the Community Earth System Model (CESM) developed by Small et al. (2014)]. In particular, the Geophysical Fluid Dynamics Laboratory (GFDL) High-Resolution ForecastOriented Low Ocean Resolution (HiFLOR), which is a highresolution atmosphere-land model $\left(0.25^{\circ} \times 0.25^{\circ}\right)$ coupled with a low-resolution ocean-sea ice model $\left(1^{\circ} \times 1^{\circ}\right.$; Murakami et al. 2015), can reproduce many features of TC climatology, including spatial distribution and intensity distribution, with good fidelity in comparison with observations (Murakami et al. 2015; Zhang et al. 2016). Previous studies using HiFLOR projections identify an increase in the TC intensification rate and a higher chance of TC rapid intensification (RI) by the end of the twenty-first century (Bhatia et al. 2018), as well as an increase in global TC frequency and in the frequency of the most intense (categories 3-5) TCs in response to increasing greenhouse gases (Bhatia et al. 2018; Vecchi et al. 2019). Not all models with grid spacing of $28 \mathrm{~km}$ or finer are able to simulate very intense (category 4 or 5) TCs (e.g., Yamada et al. 2017; Manganello et al. 2014; Knutson et al. 2008), as this capability appears to depend on both model resolution and details of model physics.

Synthetic downscaling methods, which are now commonly used for climate-TC risk studies, generate large numbers of synthetic TCs at the basin scale based on comprehensive climate conditions from reanalysis data or low-resolution GCM simulations. The pioneer of this family of methods is the statistical-deterministic method developed by Emanuel et al. (2008). This method applies a random seeding technique to initiate the storm, a beta and advection model based on synthetic local winds to propagate the storm, and a deterministic intensity model [Coupled Hurricane Intensity Prediction System (CHIPS); Emanuel and Nolan 2004] to estimate the storm intensity based on the storm environment along the track. This method has been applied to study TC properties under various climate conditions. In particular, Emanuel (2013) applies the method to downscale six CMIP5 climate projections and projects an increase in TC frequency during the twenty-first century. The method has also been widely applied to assess TC wind (Yeo et al. 2014), rainfall (Emanuel 2017), and storm surge (Marsooli et al. 2019) hazards, as well as TC economic losses (Mendelsohn et al. 2012), under current and future projected climate conditions.

Similar to Emanuel et al. (2008), the model developed by Lee et al. (2018) can also generate synthetic TCs for given climate conditions, but it is purely statistical. This model has a genesis component based on Poisson regression (Tippett et al. 2011). Its track component is based on a revised beta and advection model with the beta drift term dependent on the storm location, and its intensity component is based on multiple linear regression on key environmental parameters plus an autoregressive stochastic error term (Lee et al. 2015, 2016). Diverging TC frequency trends are projected using this method to downscale five CMIP5 climate projections, where the storm frequency will increase or decrease depending on the selection of the moisture variable (relative humidity or saturation deficit) in its genesis component (Lee et al. 2020).

Recently, a new probabilistic TC model, the Princeton Environment-Dependent Probabilistic Tropical Cyclone model (PepC), has been developed by Jing and Lin (2020). Aimed to improve on the work of Lee et al. (2018), PepC performs the Poisson regression on environment-clustering grids (rather than regular grids) to better capture the spatial-temporal variation of the storm genesis. PepC applies an analog-wind track model where storm tracks are determined based on similar historical track patterns in addition to local in situ wind, which allows the model to better capture intrinsic features such as recurving storm tracks at high latitudes. It models the evolution of a storm's intensity as a Markov process to better capture the nonlinear/nonhomogeneous response of TC intensification to the environmental change along the storm track. As a result, although most statistical TC intensity models have only limited capacity to simulate extreme TCs, PepC can simulate a realistic fraction of RI storms due to its "lock-in" mechanism, which supports continuous rapid intensification once the storm enters the extreme state of intensification when the environment is favorable. The capacity to simulate extreme TCs is essential, especially for climate change studies where a number of modeling studies suggest that higher-intensity TCs are more likely to increase in frequency than lower-intensity TCs under global warming (Knutson et al. 2020).

While widely used in climatology modeling and risk assessment, the synthetic downscaling methods described above have not been compared in terms of their TC projections under climate change scenarios. These synthetic downscaling methods are fully (Lee et al. 2018; Jing and Lin 2020) or 
partially (Emanuel et al. 2008) statistical. It is important to compare their TC climatology projections with those based on full dynamic modeling (Emanuel et al. 2010). Also, most existing TC projections were driven by varying environmental conditions (generated from different climate models and/or for different emissions scenarios; Knutson et al. 2020); comparisons among TC projections that are driven by the same environmental condition are limited. By holding the environmental condition fixed across the methods, any differences in response are due to factors other than differences in the large-scale TC environment as simulated by climate models. In addition to their practical importance, such comparisons may also contribute to our understanding of how TCs will respond to climate change.

In this study, we apply both the PepC of Jing and Lin (2020) and the statistical-deterministic model of Emanuel et al. (2008) to generate large samples of synthetic TCs under HiFLOR projected climates for the Atlantic basin, where the PepC has been tested against observations (Jing and Lin 2020). The synthetic storms downscaled from the HiFLOR climate projections are compared with storms generated directly in HiFLOR. We use three HiFLOR experiments to represent the historical ["control" (1986-2005)] and future ["early" (201635) and "late" (2081-2100)] climates under the representative concentration pathway 4.5 (RCP4.5) scenario; these are the same experiments explored in van der Wiel et al. (2017) and Bhatia et al. (2018). In addition to examining the discrepancies in the modeling approaches and results, we investigate simulated TC characteristics under the historical and future climates to study the climate change effects. The climatology characteristics we focus on include storm basin-wide annual frequency, track density, and lifetime maximum intensity, as well as landfall frequency, intensity, and return periods. We further discuss the modeling results in comparison with previous TC projections.

This paper is organized as follows. After this introduction, section 2 describes the high-resolution GCM applied, HiFLOR; the two downscaling techniques, those of Emanuel et al. (2008) and Jing and Lin (2020); and the downscaling experiments. Section 3 presents simulated results under current and future climates. Section 4 discusses TC frequency trend and possible attributions. Section 5 concludes the study.

\section{Data, models, and downscaling approaches}

In this section, we first describe the HiFLOR model and the three HiFLOR experiments used in this study. Next, we briefly describe the two downscaling approaches, those of Emanuel et al. (2008) and Jing and Lin (2020). The calibration methods associated with each downscaling approach are also explained.

\section{a. HiFLOR model and experiments}

In this study, we use three 70-yr HiFLOR "time slice" climate experiments (i.e., repeating climatological forcing for each simulation year, as introduced in van der Wiel et al. 2017) to represent the effects of climate change. The control experiment represents the historical climate during the period of 1986-2005, while two future climate experiments, referred to as the early and late experiments, project the climate during 2016-35 and
2081-2100, respectively. The experiments are set up with sea surface temperature (SST) relaxed to climatological SST values. The prescribed SST target in the control experiment is set as the monthly varying climatology from the Met Office Hadley Centre Sea Ice and SST dataset (HadISST1.1; Rayner et al. 2003) over 1986-2005, while the early and late experiments used the same climatological values of SSTs from the control experiment plus the projected changes in 2016-35 and 2081-2100, respectively, derived from a multimodel mean of 17 CMIP5 models, based on the RCP4.5 pathway (van Vuuren et al. 2011). The experiments cannot capture the response of TC activity to SST changes in the interannual or decadal scales. However, it is hypothesized that those variations are smaller than the response of TC activity to climatological changes in SST - a hypothesis that is supported by fully coupled and nudged-SST experiments (Vecchi et al. 2019).

TCs in HiFLOR are tracked based on warm-core temperature, sea level pressure, and 10-m wind. This tracker, developed by Harris et al. (2016), is applied to 6-hourly instantaneous output from the model using the parameter values of Zhang et al. (2016), Murakami et al. (2015), Bhatia et al. (2018), and Vecchi et al. (2019). Specifically, the tracker follows local sea level pressure minima, and TCs are identified using a wind speed threshold $\left(17.5 \mathrm{~m} \mathrm{~s}^{-1}\right)$ and a warm core threshold of $2 \mathrm{~K}$ within $1^{\circ}$ of the storm center. TCs are required to have a 72-h total detection lifetime with at least 48 cumulative hours with a warm core and 36 consecutive hours with peak winds exceeding $17.5 \mathrm{~m} \mathrm{~s}^{-1}$, and location of TC genesis should be equatorward of $40^{\circ}$. HiFLOR TCs are shown to closely resemble the observational hurricane datasets, including the International Best Track Archive for Climate Stewardship (IBTrACS; Knapp et al. 2010) and the advanced Dvorak technique-Hurricane Satellite-B1 (ADT-HURSAT; Kossin et al. 2013), for the North Atlantic basin, which has the most reliable data quality given its superior observational network (Kossin et al. 2013; Bhatia et al. 2019). HiFLOR has been shown to produce skillful seasonal predictions of regional TC activity and category-4-5 frequency (Murakami et al. 2016). Besides TC characteristics, HiFLOR also outputs major environmental parameters including daily temperature, moisture, pressure, wind, etc., which are used to drive the synthetic downscaling.

\section{b. The statistical-deterministic method of Emanuel et al. (2008)}

This section briefly describes the statistical-deterministic downscaling method, and we refer readers to Emanuel et al. (2008) for more details of the model. First, storms are initialized with random seeding in space and time, and each seed is randomly assigned an initial wind speed that is less than $25 \mathrm{kt}$ $\left(1 \mathrm{kt} \approx 0.51 \mathrm{~m} \mathrm{~s}^{-1}\right)$. The random seeding rate is tapered down near the equator, in proportion to the low-level absolute vorticity, to prevent storm formation close to the equator. Next, storm movements are determined by a beta and advection model driven by large-scale background winds synthetically generated from a global model projection or reanalysis dataset and beta drift approximated as a function of latitude (in the updated version of the model used in this study). Then, the wind field of each storm is predicted using an 
atmosphere-ocean coupled model, CHIPS, which has very high radial resolution of the critical inner-core region and can resolve high-intensity storms. This simplified deterministic intensity model is computationally efficient, making it possible to generate very large numbers of TCs at a low computational cost. It is noted that the random seeding technique in Emanuel et al. (2008) does not produce an absolute rate of genesis per unit time per unit area; therefore, the genesis rate is often calibrated by setting the annual global or basinwide number of genesis events under the control climate to the observed genesis rate in the historical period. The calibration constant obtained from the control climate is then used as a multiplicative factor for the future climate experiments. This statistical-deterministic downscaling method is shown to generate synthetic storms that are in statistical agreement with observations (Emanuel et al. 2006). There are in total 1151, 1095, and 1049 storms generated from the statistical-deterministic model under the control, early, and late experiments for the North Atlantic basin in this study.

\section{c. PepC of Jing and Lin (2020)}

The PepC model developed in Jing and Lin (2020) is also used to perform downscaling of HiFLOR under each climate condition. PepC consists of a clustering-based genesis model, an analog-wind track model, and a Markov-based intensity model. The genesis model seeds weak vortices in the basin based on Poisson regression on the environmental parameters including potential intensity [PI; derived following Emanuel (1995) and Bister and Emanuel (1998, 2002)], deep layer vertical wind shear (SHR), low-level relative vorticity (VO), and saturation deficit [derived following Emanuel et al. (2008)], over clustering grids that are determined by the similarity of these local environmental conditions. As compared with Emanuel et al. (2008), where the genesis seeding does not evolve with climate change, ${ }^{1}$ the genesis distribution in Jing and Lin (2020) is highly dependent on climate variables. We use saturation deficit as the humidity predictor in this study on climate change impact given that theoretically saturation deficit better reflects the increase in the thermodynamic inhibition of TC formation in a warming climate (Emanuel et al. 2008), although Jing and Lin (2020) show that using relative humidity fits better statistically with the observations under the current climate. After initialization, the seeds are passed to an analog-wind track model, in which a storm's movement is determined by both analog factors (from historical track patterns) and local in situ winds. The wind predictors are similar to those in the beta and advection model in Emanuel et al. (2008) and are derived from large-scale global model or reanalysis wind fields.

The storm's intensity is determined by the Markov environmentdependent hurricane intensity model (MeHiM), which simulates TC intensity evolution over the ocean as a Markov process (Jing and Lin 2019). MeHiM considers three unobserved (hidden) discrete states of intensification and associates each state with a probability distribution of intensity change. The three unobserved

\footnotetext{
${ }^{1}$ Aside from minor changes in seeding rate near the equator that result from possible changes in the absolute vorticity of the lowlevel flow there.
}

discrete states, referred to as the static, moderate, and extreme states, represent the storm's slow, normal, and rapid intensity changes, respectively. The storm's transit from one state to another is described as a Markov chain. Both the intensity change and state transit components of the MeHiM are dependent on environmental variables, including PI, SHR, relative humidity (RH), and an ocean feedback parameter [incorporating vertical profiles of oceanic temperature and salinity; derived following Schade and Emanuel (1999)], in addition to the storm's last step intensity change and current intensity. Jing and Lin (2019) show that it is important to include in MeHiM an ocean feedback parameter to represent the ocean's cooling effect, which is often omitted in other statistical downscaling methods (Murakami et al. 2012; Korty et al. 2017). The ocean feedback parameter, included in the MeHiM used in this study, is also estimated from HiFLOR. A simple land model [similar to Kaplan and DeMaria (1995); see more details in Jing and Lin (2019)] is added to estimate intensity decay as a function of time when the storm moves over land.

The original PepC model in Jing and Lin (2020) is developed based on observational reanalysis data, and the simulated results compare well to observations (Jing and Lin 2020). When applied to downscale climate model projections, however, PepC may produce biased results due to possible biases in the climate model projections. To focus on the climate change effects based on the HiFLOR simulations in this study, therefore, we "calibrate" PepC by adjusting each of its model components to capture the HiFLOR climate-TC relationships in the control experiment. That is, we redevelop each of the genesis, track, and intensity components of PepC based on HiFLOR simulated storms and the environment in the control experiment. Then we apply the fitted model to generate synthetic storms for each of HiFLOR control and future climate experiments. There are in total 36232, 39997, and 41131 storms generated from PepC under the control, early, and late experiments for the North Atlantic basin in this study.

\section{Results}

In this section, we investigate the response of simulated TCs to climate change in each dataset moving from the control to the early and late experiments. The HiFLOR model-generated TCs are detected by a strict detection algorithm, as mentioned above. To be consistent with HiFLOR, we filter the synthetic TCs generated by downscaling techniques in Emanuel et al. (2008) and PepC to include only storms that last at least $72 \mathrm{~h}$ and have at least 36 consecutive hours of winds greater than $34 \mathrm{kt}$. To make it simple, in the following sections, we use the name HiFLOR to specifically refer to the TCs that are explicitly simulated in HiFLOR experiments. We denote the TC dataset downscaled from HiFLOR experiments with the Emanuel et al. (2008) approach as KE08 and the TC dataset downscaled with the Jing and Lin (2020) approach as PepC. The observational TC data in the period of 1986-2005, taken from the IBTrACS WMO archive (Knapp et al. 2010), are used as a reference. The data include 6-hourly latitude and longitude positions as well as 10-min maximum sustained wind speeds at $10 \mathrm{~m}$ above the sea surface for each storm. The observational dataset is denoted simply as IBTrACS. We compare KE08 and 


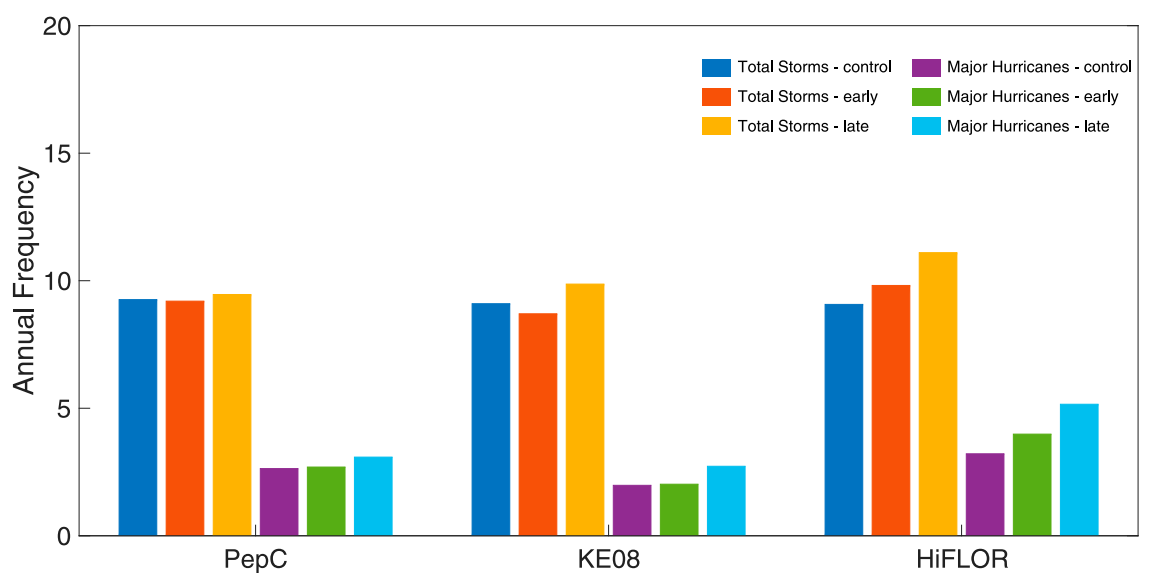

FIG. 1. Annual frequency of total storms and major hurricanes (wind speed $>95 \mathrm{kt}$ ) for HiFLOR, KE08, and PepC in the control (1986-2005) and climate change experiments (201635 and 2081-2100, the early and late experiments, respectively).

PepC to HiFLOR to discuss the TC differences between synthetic downscaling and original climate model projections under the same climate environments (HiFLOR control and climate projections under RCP4.5). We present IBTrACS as only a reference to possibly detect the effects of biases in the HiFLOR climate estimation.

\section{a. Annual frequency and genesis distribution}

We first examine the annual frequency of Atlantic storms from HiFLOR, KE08, and PepC. There are on average 9.1 storms per year in HiFLOR under the control experiment, which is comparable to 10.15 storms per year in IBTrACS. There are 11.8 and 7.25 storms per year in KE08 and PepC under the control experiment, respectively. The original genesis frequency in PepC (9.3) is close to that in HiFLOR, as the genesis component in PepC is developed based on HiFLOR genesis under the control experiment. However, only $78 \%$ of the storms develop to meet the storm selection criteria described above. It is also noted that the storm frequency in KE08 is larger than the other datasets. The genesis in KE08 is generated through random seeding, which is calibrated with the observed global frequency. Here, to focus on the climate change effects, we further calibrate TC frequency in PepC and KE08 to be consistent with HiFLOR in the control experiment for the North Atlantic basin. Specifically, we apply a multiplicative factor of 0.77 to KE08 and of 1.3 to PepC, for both the control experiment and future climate projections. The resulting estimations of annual frequency of total storms and major hurricanes (discussed later) for the three models appear in Fig. 1.

To determine whether the change of storm frequency from the control to climate change scenarios is statistically significant, we perform hypothesis testing of equal frequency for each dataset. The two-sample, unpaired $t$ test (Wilks 2011) is computed for HiFLOR and KE08, and a $p$ value of 0.05 is set as the threshold for statistical significance. To adjust for multiple comparisons (we have 100 realizations of PepC downscaling, and each realization is compared with HiFLOR for the hypothesis test), the Benjamini and Yekutieli $(2001,2005)$ procedure of controlling the false discovery rate (FDR) of a family of hypothesis tests is performed for PepC, with the same statistical significance threshold of $p$ value of 0.05 . When the $p$ value is less than the threshold of 0.05 , we reject the null hypothesis and consider the change in TC frequency statistically significant. Statistically significant change in TC frequency indicates that the change is very likely not induced by randomness. As shown in Table 1, HiFLOR has a significant increase of storm frequency in the late experiment relative to the control experiment $(+22.4 \%)$, while the increase in the early experiment $(+8.2 \%)$ is not statistically significant. Similar but to a lesser extent, KE08 has a significant increase in the storm frequency in the late experiment relative to the control experiment $(+8.5 \%)$; however, KE08 has a nonsignificant decrease in the early experiment $(-4.4 \%)$. PepC has a nonsignificant decrease $(-0.6 \%)$ in the storm frequency in the early experiment and a nonsignificant increase $(+2.2 \%)$ in the late experiment.

In addition to the annual frequency, the spatial distributions of TC genesis in the datasets under the control experiment are shown in Fig. 2. When compared with HiFLOR, KE08 shows a similar genesis pattern; however, the maximum in the main development region (MDR; $10^{\circ}-20^{\circ} \mathrm{N}, 80^{\circ}-20^{\circ} \mathrm{W}$ ) is slightly shifted to the east, and slightly more storms are generated in the Gulf of Mexico and Caribbean regions. PepC captures genesis pattern in HiFLOR, although the storms are much less concentrated in the MDR and spread more to the middle of the Atlantic. The genesis schemes for KE08 and PepC are quite different. In KE08, as the storms are randomly seeded everywhere (with the exception of tapering near the equator), the spatial pattern of genesis indicates that the storm survival rate in the MDR is much higher than in any other regions. However, in PepC where storms are initiated based on local climate conditions, the genesis spatial distribution is determined by both the initial distribution and survival rate.

Historically, the majority of storms form in the MDR, but secondary maxima of activity are seen off the U.S. southeast coast and in the Gulf of Mexico (Fig. 2a). The control simulations capture the maximum in the MDR with the hotspot shifted to the west of the MDR. However, the simulations do 
TABLE 1. The percent difference of the number of total storms, major hurricanes, category-4 hurricanes, category-5 hurricanes, and number of storms that undergo RI in HiFLOR, KE08, and PepC, between the HiFLOR climate change simulations and the HiFLOR control simulation. For each storm type, the first entry in the table cell is the percent difference between the 2016-35 and 1986-2005 simulations, and the second entry is the percent difference between the 2081-2100 and 1986-2005 simulations. Positive values indicate percent increases in the climate change simulation. Statistically significant changes are in boldface type.

\begin{tabular}{|c|c|c|c|c|c|c|c|c|c|c|}
\hline & \multicolumn{2}{|c|}{ Total storms } & \multicolumn{2}{|c|}{ Major hurricanes } & \multicolumn{2}{|c|}{ Category 4} & \multicolumn{2}{|c|}{ Category 5} & \multicolumn{2}{|c|}{ RI storms } \\
\hline & Early & Late & Early & Late & Early & Late & Early & Late & Early & Late \\
\hline HiFLOR & $+8.2 \%$ & $+22.4 \%$ & $+24.0 \%$ & $+60.4 \%$ & $+30.4 \%$ & $+103.2 \%$ & $+60.0 \%$ & $+\mathbf{5 4 0 . 0} \%$ & $+39.6 \%$ & $+76.0 \%$ \\
\hline KE08 & $-4.4 \%$ & $+8.5 \%$ & $+2.2 \%$ & $+37.8 \%$ & $-21.1 \%$ & $+13.3 \%$ & $+108.3 \%$ & $+250.0 \%$ & $-11.2 \%$ & $+20.5 \%$ \\
\hline PepC & $-0.6 \%$ & $+2.2 \%$ & $+2.3 \%$ & $+17.1 \%$ & $+4.2 \%$ & $+29.4 \%$ & $+1.1 \%$ & $+53.6 \%$ & $+1.8 \%$ & $+10.8 \%$ \\
\hline
\end{tabular}

not produce much concentrated activity along the U.S. coast or in the Gulf of Mexico, as shown in IBTrACS, probably due to the bias in the simulated climate environment. The statistical significance of these differences cannot be easily tested given the limited sample size in IBTrACS at the local scale. It is worth mentioning that the spatial distribution of genesis in KE08 is similar to that in Emanuel et al. (2008) when the synthetic storms are downscaled from the reanalysis data, indicating that the random seeding technique is relatively stable and less sensitive to changes and potential biases in the climate estimation. No significant changes in TC genesis locations are identified in the future climate projections (figures not shown).

\section{b. Track density and landfall frequency}

Figure 3 compares the track density of the datasets for the control experiment. TC track density is calculated by counting the number of times per year that TC tracks pass each $5^{\circ} \times 5^{\circ}$ grid cell. The track density plot of IBTrACS is also shown as a reference. Although the track density is highly affected by the genesis distribution (Fig. 2), the track density in PepC compares closely to that in HiFLOR, as PepC tracks depend on HiFLOR's track pattern and environmental wind. Both have a single maximum in the western North Atlantic around $25^{\circ} \mathrm{N}$, $70^{\circ} \mathrm{W}$; both show the typical recurving pattern in tracks, although storms in PepC recurve slightly earlier than those in HiFLOR. Also, the track distributions in both HiFLOR and PepC have a tongue extending toward the Gulf of Mexico, although the tongue in HiFLOR is slightly larger than that in PepC. The track density of KE08 is quite different from those of HiFLOR and PepC, although the genesis distribution in KE08 is similar to that in HiFLOR (Fig. 2). There are many more storms in KE08 that travel toward Gulf of Mexico, while many fewer are recurving to high latitudes, which results in a stronger maximum appearing in the Gulf of Mexico relative to HiFLOR and PepC. This difference is likely due to the fact that the track component in Emanuel et al. (2008) depends mainly on the environmental wind, which is synthetically generated based on the monthly wind climatology from HiFLOR, and the
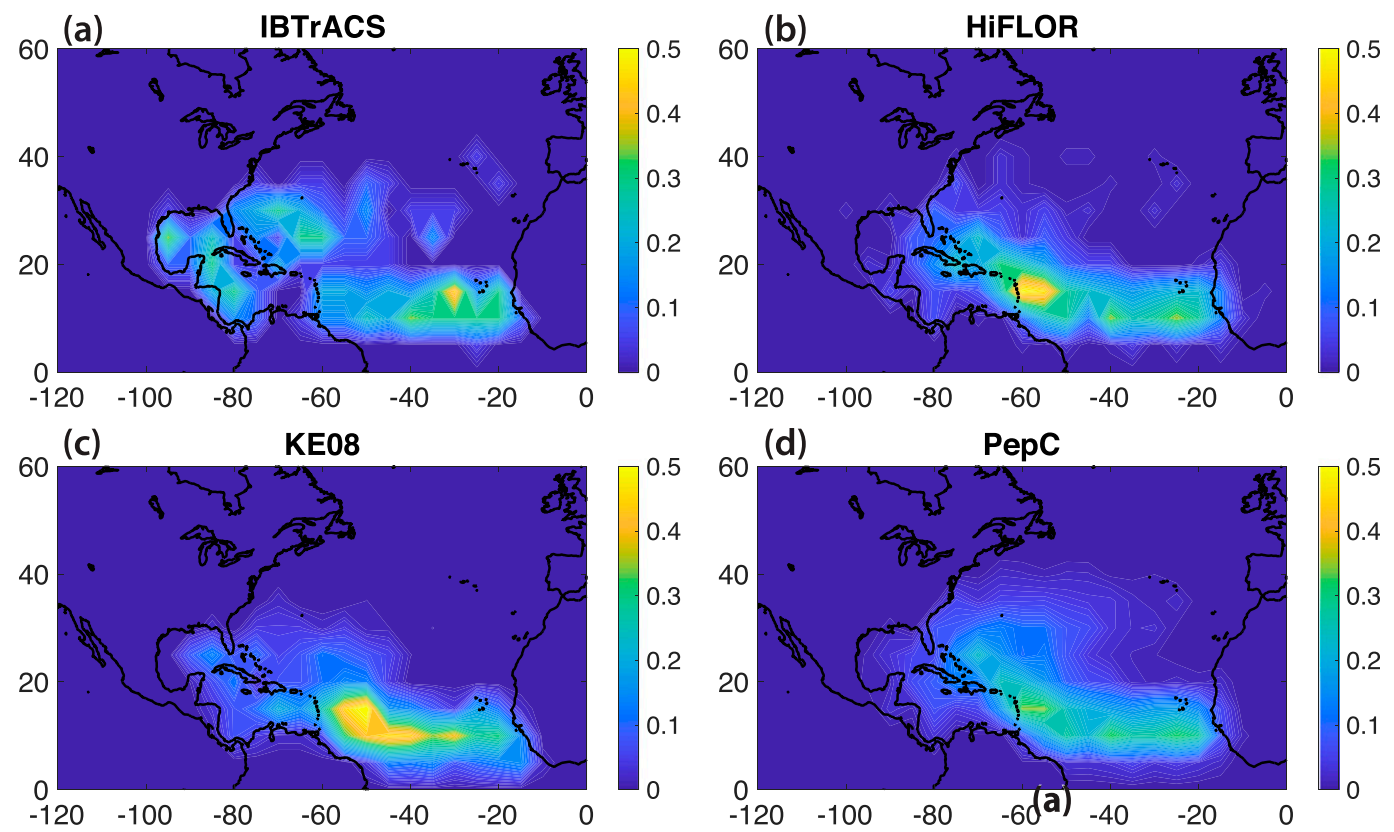

FIG. 2. Comparison of the spatial distribution of genesis in (a) IBTrACS, (b) HiFLOR, (c) KE08 and (d) PepC in the control experiment. Color indicates the number per year of storms in each $5^{\circ} \times 5^{\circ}$ grid box (after calibration) smoothed with a Gaussian low-pass filter. 

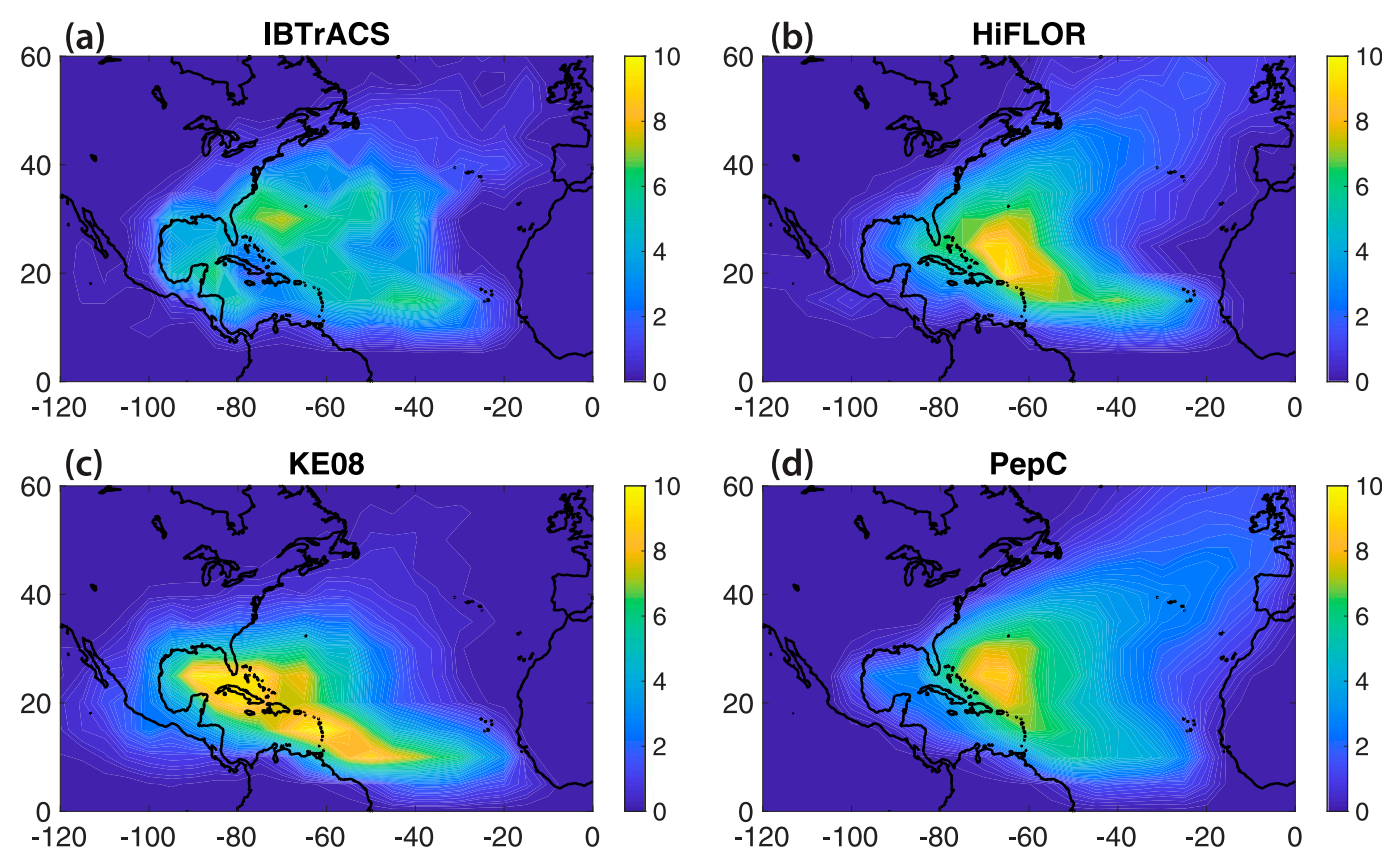

FIG. 3. Comparison of track density in (a) IBTrACS, (b) HiFLOR, (c) KE08, and (d) PepC under the control experiment. Track density is calculated as the number of times per year that TC tracks pass into each $5^{\circ} \times 5^{\circ}$ grid box smoothed with a Gaussian low-pass filter.

effect of beta drift is approximated as only a simple function of latitude. Relative to IBTrACS, HiFLOR's and PepC's maxima in western North Atlantic are large and shifted away from the U.S. southeast coast, whereas for KE08 the track density is more highly concentrated along a path between the MDR and the Gulf of Mexico; these modeling errors are induced by a mixture of uncertainties in the TC models and HiFLOR climate estimation. It should also be noted that the synthetic downscaling simulations do not include hybrid storms, which are present in the observations and possibly also in the HiFLOR simulations.

We further examine regional annual landfall frequency at coastal locations along the western North Atlantic coastline. To help indicate locations, a total of 186 mileposts (MPs) is defined, following Vickery et al. (2000) and Jing and Lin (2020), to cover the coastline with $100-\mathrm{km}$ spacing along the Mexican coastline and 50-km spacing along the U.S. coastline, as shown in Fig. 4. Here, landfall is defined as the passing of a storm within $100 \mathrm{~km}$ of each milepost. As shown in Fig. 5a for the control experiment, the simulated annual landfall frequencies of KE08 and PepC are compared with those of HiFLOR for the mileposts. (Given its limited sample size at the local scale, IBTrACS is not used for comparison here.) In general, KE08 has a correlation coefficient of 0.55 with HiFLOR, as compared with 0.80 of PepC with HiFLOR. PepC is in good agreement with HiFLOR in terms of variations for almost all mileposts. However, it shows a slight overestimation near MP 40-50 but a negative bias to the north of MP 50, likely due to the fact that storms in PepC tend to recurve earlier (Fig. 3). KE08 shows larger variations. In all regions south of MP 100 (west of Florida), KE08 has much higher landfall frequency than HiFLOR and PepC, while in regions north of MP 100 the landfall frequency of KE08 drops dramatically and becomes much lower than that of HiFLOR, close to PepC to the north of MP 120. These results are also consistent with the track density plot as shown in Fig. 3, where most storms in KE08 travel to the Gulf of Mexico.

Figures 5b-d compare the TC annual landfall frequency at the 186 mileposts in the control and climate change experiments. We find that the climate change effect on landfall frequency is relatively small in comparison with the variation of the predictions among the models. HiFLOR is the most sensitive to climate change, with some increases shown in the early experiment for the south of MP100 (south of Florida) and in the late experiment for the north of MP100, while PepC shows the least sensitivity with almost no change except for a slight increase in the late experiment for MP 80-110, which represents the Florida area. It is interesting to find that even though a significant increase exists in the frequency of total TCs in HiFLOR and KE08 $(+22.4 \%$ and $+8.5 \%$, respectively; Table 1), changes in their landfall frequency appear to be smaller.

\section{c. LMI, rapid intensification rate, and landfall intensity}

Next, we examine the intensity properties of the simulated storms. Figure $6 \mathrm{a}$ shows the probability density functions (PDFs) of TC lifetime maximum intensity (LMI) for storms in HiFLOR, KE08, and PepC in the control experiment. The LMI distribution of HiFLOR follows a bimodal distribution, with the first peak located at about $75 \mathrm{kt}$. In HiFLOR, about $35 \%$ of TCs reach major hurricane intensities, and around $1 \%$ grow to a category-5 (LMI > $136 \mathrm{kt})$ storm. Around $45 \%$ of 

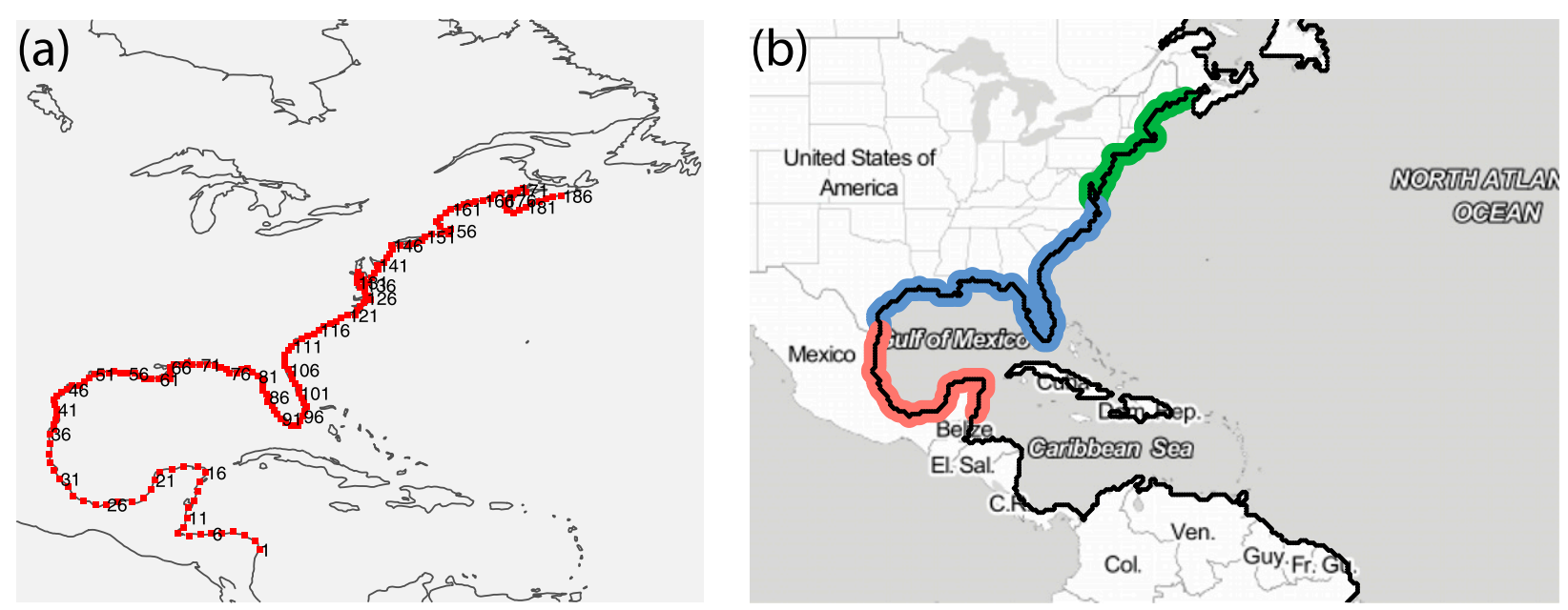

FIG. 4. Illustrations of locations and areas along the western North Atlantic coastline considered in this study: (a) locations of considered mileposts (MPs) along the Mexico (every $100 \mathrm{~km}$ ) and U.S. (every $50 \mathrm{~km}$ ) coastlines; (b) locations of four regions: the North Atlantic coastline (green, blue, and red segments shown on the map; all $186 \mathrm{MPs}$ ), the northeastern United States from Maine to Virginia (green segment; MPs 128-186), the southeastern United States from North Carolina to Florida plus the U.S. Gulf Coast (blue segment; MPs 41128), and the Gulf Coast of Mexico (red segment; MPs 1-40).

HiFLOR storms undergo RI. Relative to HiFLOR, KE08 simulates much weaker storms with the peak appearing at around $70 \mathrm{kt}$. Only $31 \%$ of storms undergo RI during their life cycle, and only $22 \%$ of storms reach major hurricane intensity. However, $1 \%$ become the most intense category- 5 storms, which is similar to HiFLOR. PepC stands in the middle between HiFLOR and KE08. It also follows a bimodal distribution, with the first peak, however, close to that of KE08. Generally speaking, there are more storms with moderate LMI in PepC than in KE08 and HiFLOR. Around $28 \%$ of PepC storms reach major hurricane intensity, 33\% undergo RI, and 1\% grow to category 5 .

The LMI of IBTrACS is also shown in Fig. $6 \mathrm{a}$ as a reference. Historically, $30 \%$ of storms reach major hurricane intensity, about $4 \%$ grow to category 5 , and around $45 \%$ undergo RI. Relative to observations, there are fewer weak and very strong storms in HiFLOR (and also in PepC), and the LMIs are more concentrated in a narrower range. This inconsistency could be partially induced by the detection algorithm, as the warm-core requirements and other components of the detecting procedure in HiFLOR may have lowered the number of weak TCs, which shifts the first peak of the LMI distribution to a higher value. It is noted that these results are very similar to findings in Bhatia et al. (2018), in which a similar HiFLOR simulated storm dataset is used. All three simulations underestimate the tail of LMI as shown for IBTrACS.

We then examine the PDFs of TC LMI in HiFLOR, KE08 and $\mathrm{PepC}$ in the early and late experiments. In all three datasets, the entire LMI distributions shift to higher intensity values in climate change experiments. However, HiFLOR has the largest
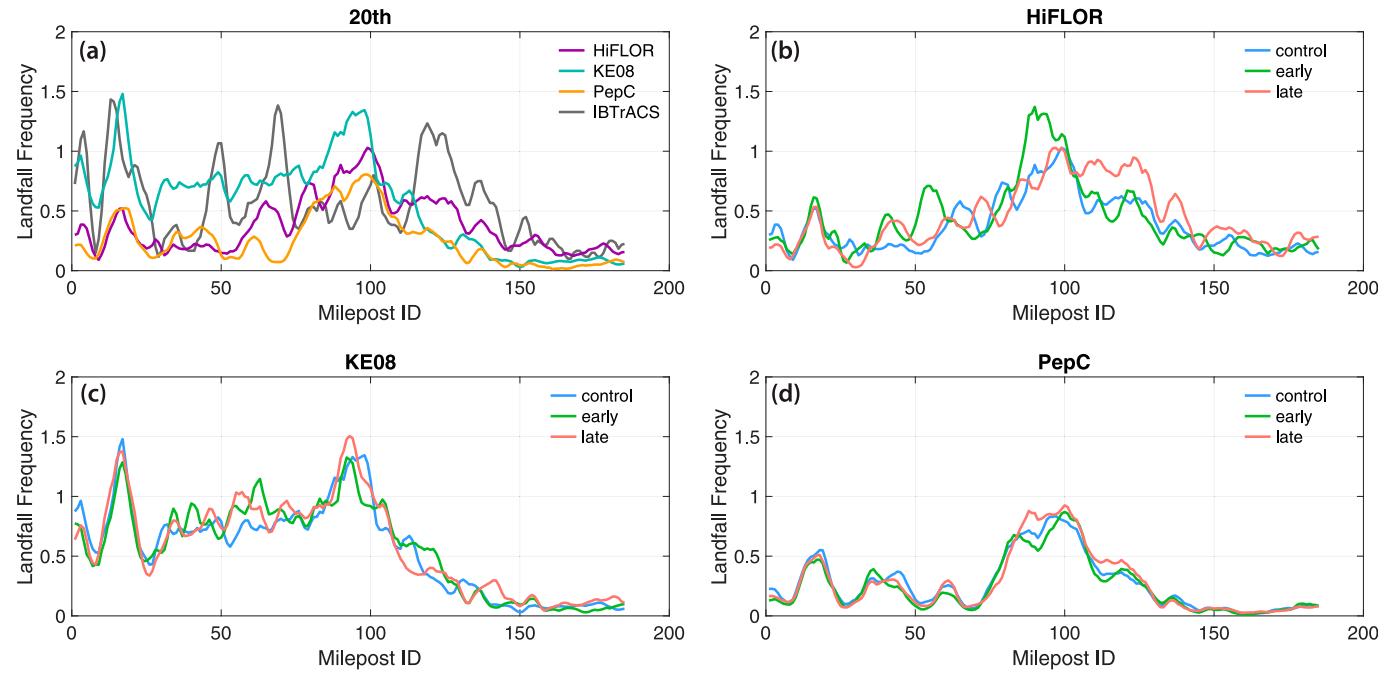

FIG. 5. Comparison of annual landfall frequency at each of the 186 mileposts (as shown in Fig. 4) along the western North Atlantic coastline (a) under the control experiment and (b)-(d) for each dataset under the warming climate. 

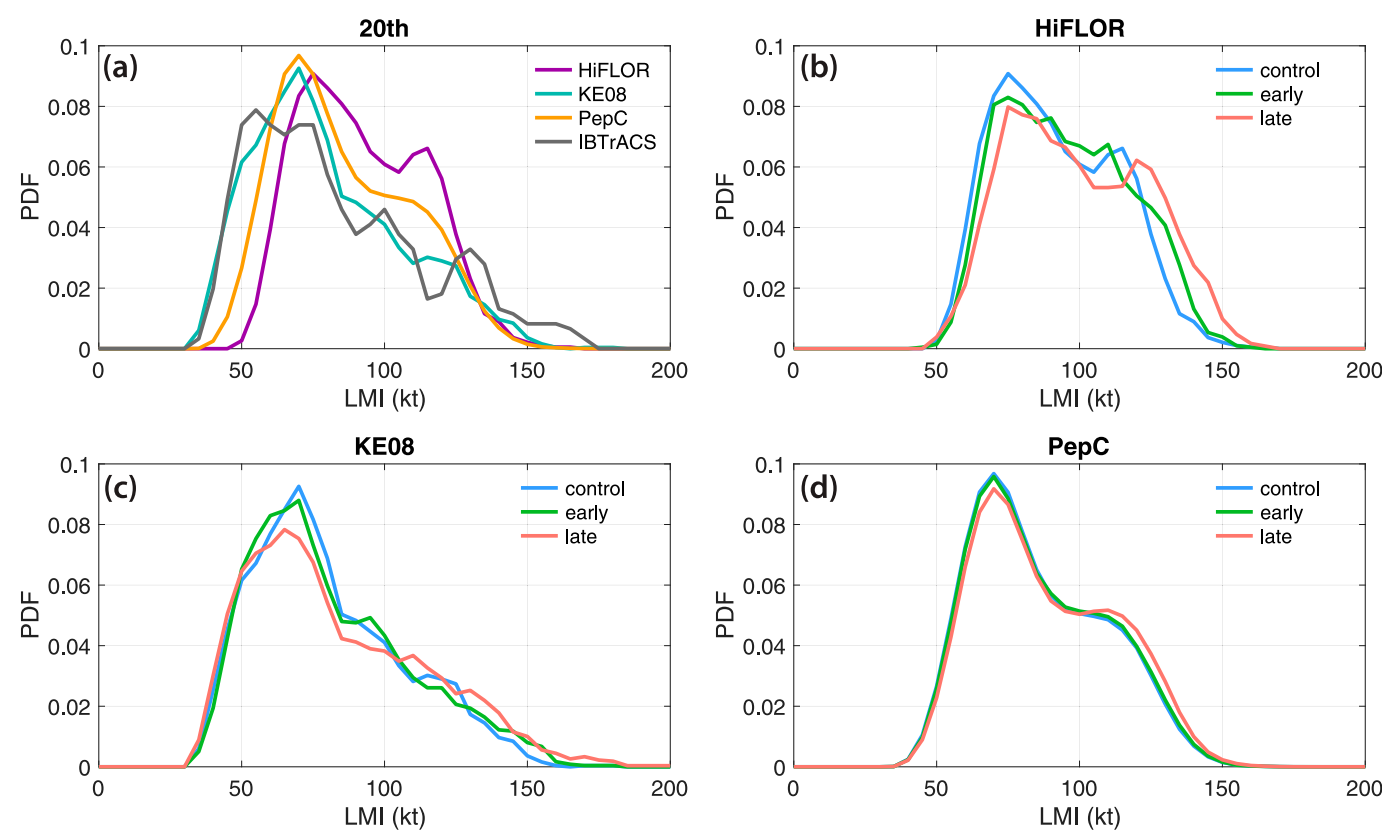

FIG. 6. Comparison of PDF of lifetime maximum intensity in (a) the control experiment and (b)-(d) for each dataset under the warming climate. Raw data are grouped in 5-kt bins and smoothed by a moving average window with width of $15 \mathrm{kt}$.

change while PepC has the least change (Figs. 6b-d). As shown in Fig. 1 and Table 1, HiFLOR has significantly more major hurricanes in the early $(+24 \%)$ and late experiments $(+60.4 \%)$ than in the control experiment. HiFLOR has particularly large increases in category $4(+103.2 \%)$ and category $5(+540 \%)$ in the late experiment. These results are consistent with the analysis in Bhatia et al. (2018) for the North Atlantic basin. To a lesser extent, KE08 shows significant increases in the major hurricanes $(+37.8 \%)$ and category-5 storms $(+250 \%)$ in the late experiment. Similar to HiFLOR, PepC projects increases in major hurricanes $(+17.1 \%)$, category-4 storms $(+29.4 \%)$, and category $-5(+53.6 \%)$ storms in the late experiment; the changes are much smaller but still significant.

Because most category-4 and category-5 storms undergo RI during their life cycles, we further investigate the change in RI storms. HiFLOR has a significant increase of the RI storms in both the early $(+39.6 \%)$ and late $(+76 \%)$ experiments. KE08 and PepC have significant increases of the RI storms in only the late experiment $(+20.5 \%$ and $+10.8 \%$, respectively). Related to the differences in the RI rate among the three datasets, there are around $24 \%, 11 \%$, and $14 \%$ category- 4 storms and $4 \%, 5 \%$, and $1 \%$ category-5 storms projected in HiFLOR, KE08, and PepC, respectively, leading to very different tails (LMI $>125 \mathrm{kt}$ ) of the LMI distributions among the three datasets in the late experiment although these tails are very similar in the control experiment (Fig. 6).

Next, we investigate the probability distribution of the landfall intensity for the North Atlantic coastline and its divisions including the Gulf Coast of Mexico, the U.S. Northeast, and the U.S. Southeast (Fig. 7, with the definition of regions denoted in Fig. 4). In this case, TC landfall is defined as crossing the coastline for each region. In the control experiment, in contrast to the LMI case, where PepC stands in the middle of HiFLOR and KE08,
PepC has a higher portion of intense landfalling hurricanes, especially when the landfall intensity is greater than $70 \mathrm{kt}$. Landfalling TCs in HiFLOR are weaker than those in PepC, followed by those in KE08, which have the lowest landfall intensities, with the peak of the distribution located around $35 \mathrm{kt}$ (although IBTrACS has an even lower peak around $25 \mathrm{kt}$ ). The distributions of landfall intensity in the three subregions have similar patterns to those for the entire North Atlantic coastline, except that in the U.S. Northeast the distribution of KE08 is more significantly left-shifted than in either PepC and HiFLOR. This discrepancy can be explained by the difference in the TC tracks, as shown in Fig. 3. As most storms in KE08 travel to the Gulf of Mexico, fewer storms grow, intensify, and eventually make landfall in the northeastern region. In comparison with IBTrACS, the simulations, especially HiFLOR and PepC, have higher landfall intensity except at the very end of the tail, which is consistent with the LMI properties (Fig. 6a).

There is not much change in the landfall intensity when the climate moves from the control experiment to the early and late experiments, as shown in Fig. 7. We identify only slight shifts toward large-intensity values in the northeastern and southeastern United States in all three datasets. However, all changes fail the two-sample Kolmogorov-Smirnov test on differences in distributions and are hence statistically negligible. Referring to Table 1 and Fig. 6, storms are projected to become more intense overall, especially in HiFLOR, but this intensification does not carry over to landfall at regional or basin scale in the three simulation datasets.

\section{d. Return period of landfall intensity}

Combining the landfall frequency and landfall intensity distribution, we compute return periods for landfall intensities 

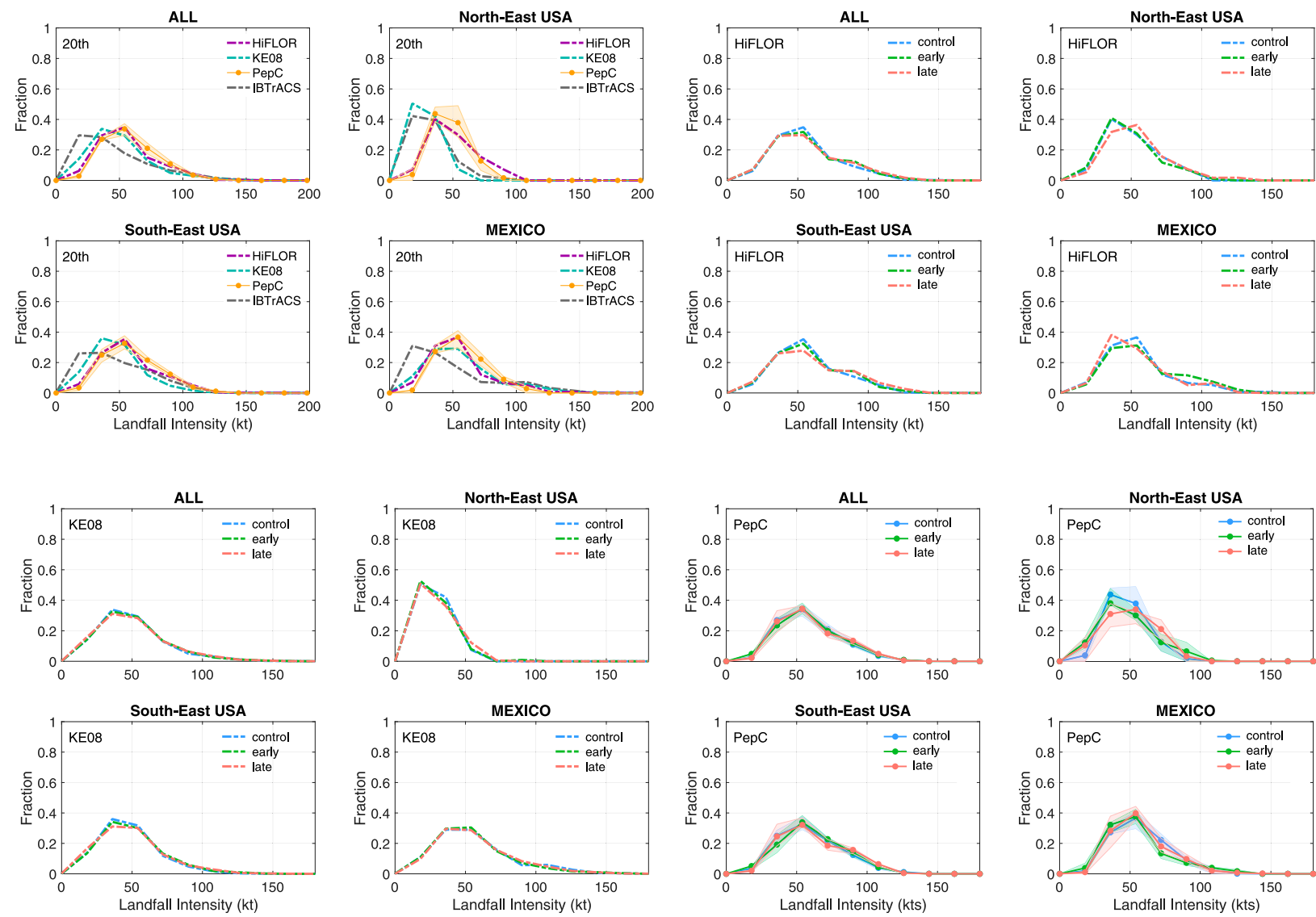

FIG. 7. PDF of TC landfall intensity in the control, early, and late experiments. The four panels on the top left are comparisons of historical records (IBTrACS) with HiFLOR, KE08, and PepC in the control experiment. Other panels show climate effects on landfall intensity for HiFLOR, KE08, and PepC. Four regions defined in Fig. 4 are examined. In PepC, the shadings show 25th-75th percentile uncertainty bounds estimated from 100 realizations. TC landfall is defined as crossing the coastline for each region.

to describe potential TC threat along the North Atlantic coastline. The return period for an intensity level is the inverse of the corresponding annual exceedance probability, which describes the chance of one or more TCs making landfall with an intensity greater than the intensity level in any given year (under a specific climate condition). The annual exceedance probability is calculated as the product of landfall frequency and exceedance probability of the landfall intensity. We show TC landfall intensity as a function of return period for each of the segments of the North Atlantic coastline (illustrated in Fig. 4, where TC landfall is defined as crossing the coastline for each region), for each model and climate condition.

The return period curves of HiFLOR, PepC, and KE08 are shown in Fig. 8. The return period curves for IBTrACS are also shown in Fig. 8 as a reference. In the control experiment, for the North Atlantic coastline, the return period curve in PepC is the lowest, KE08 is the highest, and HiFLOR stands in the middle; IBTrACS is covered by the model spread. The return period curves for the northeastern United States are more spread out, with KE08 the lowest, HiFLOR the highest, and PepC in the middle and being closest to IBTrACS. The return period curves for the Mexico are also spread out, and KE08 is much higher than HiFLOR and PepC but happens to be the closest to IBTrACS. In the U.S. Southeast, the three datasets agree with each other and with IBTrACS, and the return period curves almost overlap. As the landfall intensity distributions for the three datasets are similar for Mexico (Fig. 7a), the much higher return period curve in KE08 is induced by its estimated much higher landfall frequency for this region (as indicated in Figs. 5a and 3). For the Northeast, the much lower return period curve in KE08 is induced by its estimated much lower landfall frequency (see Fig. 5a) and landfall intensity (Fig. 7a). The estimated lower frequency in PepC than in HiFLOR for the Northeast (see Fig. 5a) also induces a lower return period curve for the region. The return periods for the North Atlantic coastline seem to be largely determined by those for Mexico and the southeastern United States.

Next, we compute return period curves for HiFLOR, $\mathrm{KE08,} \mathrm{and} \mathrm{PepC} \mathrm{in} \mathrm{the} \mathrm{early} \mathrm{and} \mathrm{late} \mathrm{experiments} \mathrm{to} \mathrm{in-}$ vestigate their responses to climate change. Overall, there is little systematic change of the landfall intensity return period under future climates relative to the current climate, especially at the basin scale. The relatively unchanged return periods result from the nonsignificant change in landfall intensity (Fig. 7) and in landfall frequency for most cases. The change in landfall frequency is 

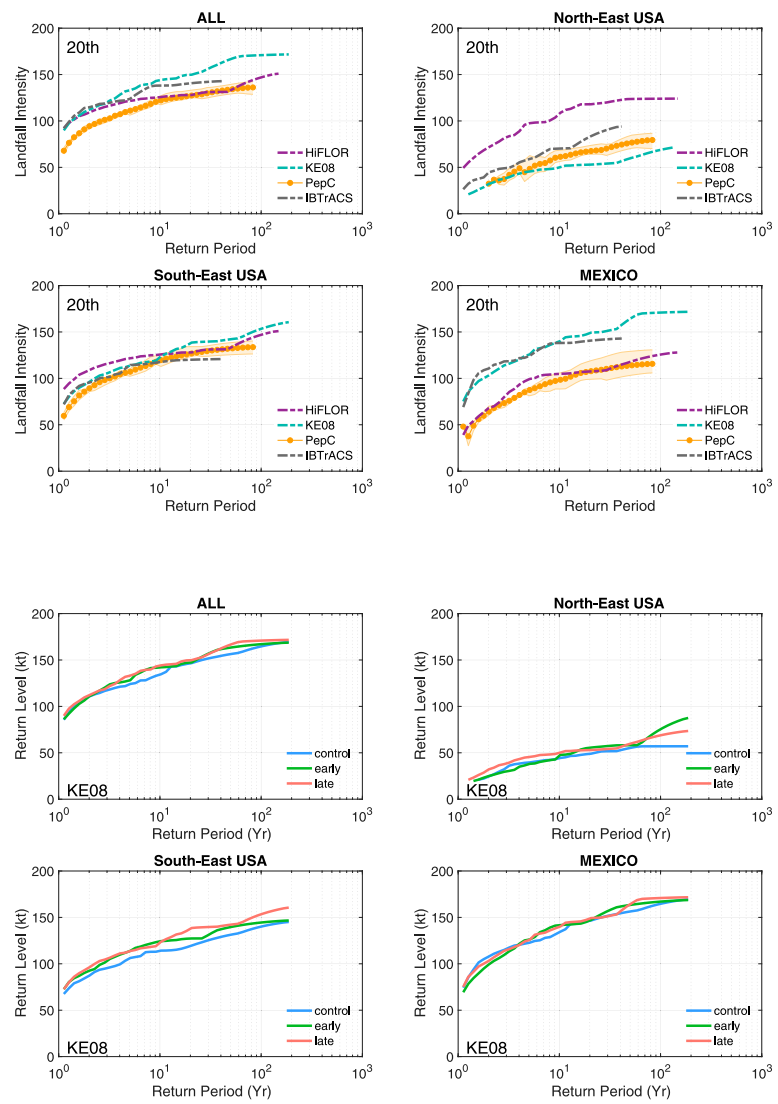

FIG. 8. As in Fig. 7, but for the return period of TC landfall intensity.
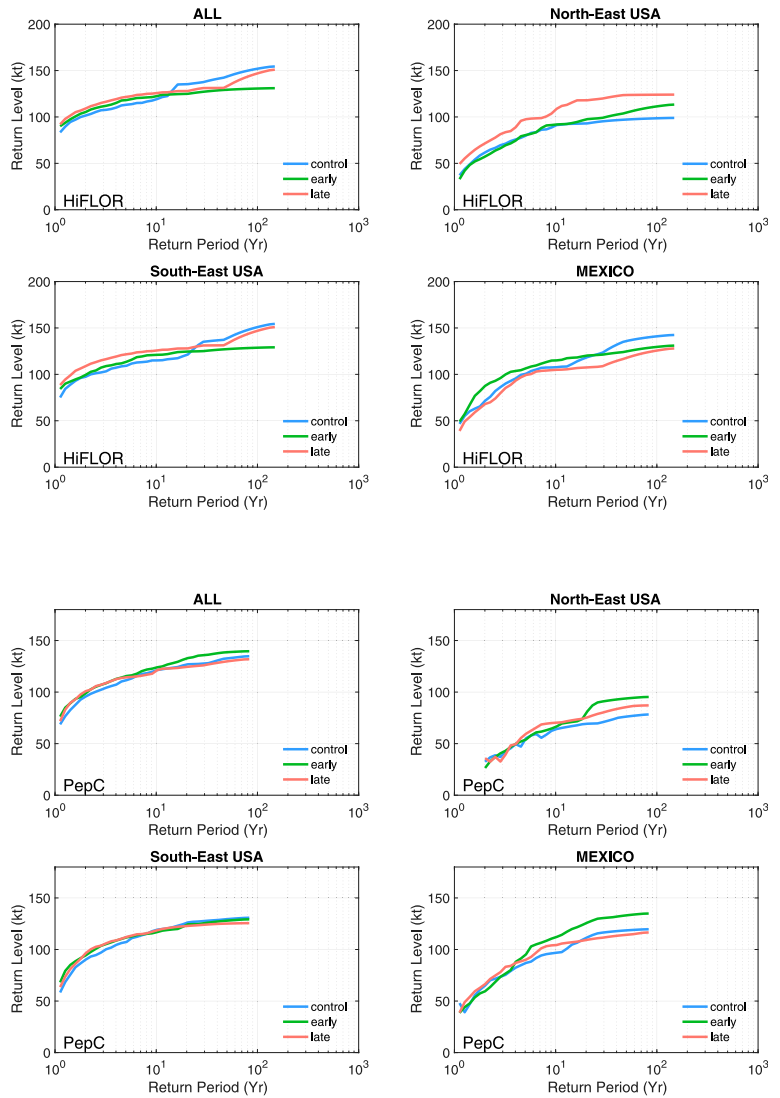

statistically significant only in HiFLOR's late experiment for the northeastern United States, based on the twosample, unpaired $t$ test (Wilks 2011). Thus, for HiFLOR (Fig. 8b), there is a moderate increase in the return level for the northeastern United States, due to the statistically significant increase in landfall frequency (see also Fig. 5b) and a nonsignificant increase in landfall intensity (Fig. 7b), and a slight decrease for Mexico in the future climate. As a result, there is little net change in the return level for the entire North Atlantic coastline. Nevertheless, the HiFLOR projection indicates that, although the northeastern region has the smallest TC threat, with the $100-\mathrm{yr}$ landfall intensity about $100 \mathrm{kt}$ under the control climate, it is the region where the TC threat may grow the fastest as the climate warms. The $100-y r$ return level is projected to be as high as $110 \mathrm{kt}$ in the early experiment and $125 \mathrm{kt}$ in the late experiment. In contrast, in Mexico the TC threat may even slightly decrease under a warmer climate. For KE08, the return level increases only slightly for the North Atlantic coastline, the southeastern United States, and Mexico, with almost no change for the northeastern United States (Fig. 8c). In contrast to HiFLOR and KE08, PepC has a slight increase in landfall intensity level for the early experiment but almost no change for the late experiment, relative to the control experiment (Fig. 8d). Overall, all three models predict the climate change effect on the landfall intensity return level/TC threat to be quite small and much smaller than the variation of the predictions among the models (Fig. 8a).

\section{Discussion}

One main objective of this study is to evaluate a new statistical synthetic downscaling approach to estimating how tropical cyclone activity will respond to climate change. Prior to this study, statistical models (describing storm genesis, track, and intensity) are usually not applied in TC climate change studies since most statistical models are climate-invariant. One exception is Lee et al. (2020), who investigate TC activity by downscaling CMIP5 climate models using the statistical model CHAZ (Lee et al. 2018). They show that the projected future TC activity is very sensitive to the choice of humidity variable (saturation deficit or relative humidity) used in the genesis component. This choice will lead to divergent conclusions about annual TC frequency trends and thus large uncertainty in regional and local storm hazard assessment. This finding reminds us that one must be cautious when using statistical methods to project TC activity under future climate conditions. Here, for the first time, we investigate statistical projections of future TC activity in comparison with dynamic and statistical-deterministic projections, all for the same environmental condition changes.

In comparing storms generated and downscaled from HiFLOR projected climate (RCP4.5), we find that HiFLOR, KE08, and 
PepC show similarities in responding to climate change in that storms will become more intense. Significant increases in the frequency of major hurricanes and category- 5 hurricanes appear in all three datasets by the end of the twenty-first century, when the fractions of RI storms are also projected to increase significantly. For total storm frequency, HiFLOR suggests a large increase, KE08 suggests a moderate (but still significant) increase, and PepC suggests no significant change by the end of the twentyfirst century. In general, the changes in PepC are usually smaller than those in HiFLOR and KE08, which means PepC is less sensitive to climate change effects. These results might indicate more generally that statistical methods are less sensitive than dynamic models to the changes in the climate environment that general circulation models project.

To further explore the causes of the uncertainties in the projections, we compare results in this study with those in the existing literature. The changes in the overall fraction of category-4-5 hurricanes in HiFLOR $(+126 \%)$ and to a lesser extent in $\mathrm{KE} 08(+46 \%)$ and PepC $(+45 \%)$ are significantly larger than the median projected global change of $+13 \%$ in previous studies (Knutson et al. 2020), although the studies assessed in the Knutson et al. (2020) include a number of lower-resolution models, where in some cases intense TC activity is inferred statistically rather than through direct simulation. Larger uncertainty exists in the projection of total storm frequency and of category-4-5 frequency. The Knutson et al. (2020) assessment suggests that the majority of dynamical modeling studies project a decline in the number of Atlantic TCs with global warming, and the model results are relatively split on whether Atlantic category-4-5 TC frequency will increase or decrease (with the caveat of the inclusion of statistically derived results from relatively lowresolution models). Analyzing eight CMIP5 climate model projections under the RCP 8.5 scenario, Tory et al. (2013) infer a mixture of TC frequency increases and decreases for the Atlantic basin, based on an empirical TC detection method. Their findings are more mixed than those of Knutson et al. (2013), who find a clear preference for a projected overall decrease in Atlantic basin TC frequency (significant for 7 of 10 individual CMIP3 models) along with a weak tendency ( 8 of 12 models) for an increase in the frequency of intense (category 4 5) TCs, using a variety of CMIP3 and CMIP5 model scenarios as the boundary forcing. [Note that the range of projections found by Knutson et al. (2013) and Tory et al. (2013) in downscaling different CMIP3 models [e.g., as shown in Table 5 of Knutson et al. (2013)] demonstrates that a wide range of projections can be driven not only by different downscaling techniques, as illustrated in the present study, but also by different climate models that supply information to the downscaling framework]. In Knutson et al. (2015), which is based on downscaling TC cases from the GFDL HiRAM global model under the RCP4.5 emission scenario, only inconclusive (nonsignificant) decreases in total TC frequency and nonsignificant increases in category-45 frequency in the North Atlantic basin are projected (Table 3 of Knutson et al. (2015). Other recent studies suggest no change or even an increase in TC frequency under the future climate. Applying a statistical downscaling scheme to 17 CMIP5 models, Villarini and Vecchi (2012) project that Atlantic TC frequency will increase in the first half of the twenty-first century, while no significant change is projected over the entire century. Their method uses only SST as the statistical predictor and does not explicitly account for changes in humidity or wind shear. Downscaling six CMIP5 models under the RCP8.5 emissions scenario using the statistical-deterministic downscaling method of Emanuel et al. (2008), Emanuel (2013) projects a consistent increase in Atlantic TC frequency and category-4-5 frequency over the twenty-first century [Atlantic basin results from Emanuel (2013) are reported in supplemental material of Knutson et al. (2020)].

A recent study explores the responses of TCs to climate change using coupled GCMs with increasingly fine resolution. While the global TC frequency decreases substantially in the 50-km model, the $25-\mathrm{km}$ HiFLOR (the same model but with different experimental designs) shows no significant change, and when model biases are corrected, HiFLOR shows a significant increase in TC frequency (Vecchi et al. 2019). Nevertheless, in comparison with previous studies, the increase of $22 \%$ in TC frequency for the North Atlantic basin in HiFLOR is exceptionally large, especially under the RCP4.5 emission scenario. Although the difference in the climate conditions may have contributed to the difference in the storm projection in HiFLOR, the main reason may be that storm activity in HiFLOR is more sensitive to climate change effects, as the increase in storm frequency of $8.5 \%$ in KE08 and no significant change in PepC $(+2.2 \%)$, given the same HiFLOR climate, are closer to the estimations in previous studies.

Multiple possible mechanisms have been discussed to explain the increment or reduction in TC frequency. Possible hypothesized mechanisms for the reduction in TC frequency include a slowing of the large-scale tropical circulation due to increasing static stability (Sugi et al. 2002; Held and Zhao 2011; Bengtsson et al. 2007) or increases in the saturation deficit between the surface and middle troposphere (Emanuel et al. 2008). On the other hand, possible mechanisms for increasing TC frequency include increases in potential intensity, and, in particular, increases in the area over which the PI is sufficiently large to sustain genesis, due to the reduction in the meridional temperature gradient and relative warming at the poleward boundaries of the historical zones of TC activity (Fedorov et al. 2018; Viale and Merlis 2017).

While the large-scale thermodynamic environment is no doubt an important factor modulating the rate of TC genesis, it is well known that real TCs often, and perhaps always, develop from pre-existing disturbances of independent physical origin. Experiments with high-resolution GCMs (Li et al. 2010; Vecchi et al. 2019; Sugi et al. 2020; Hsieh et al. 2020; Vidale et al. 2021; Yamada et al. 2021) have been used to explore such pre-existing disturbances and relate their frequency to the frequency of TCs. When these disturbances meet certain requirements, they are labeled "seeds," and their frequency is often the dominant control on overall TC frequency in comparison with the probability of their transitioning to TCs. For example, in Hsieh et al. (2020), seeds are defined as disturbances detected by a tracking algorithm whose relative vorticity lies in the interval of $4 \times 10^{-4} \mathrm{~s}^{-1}$ and $10^{-3} \mathrm{~s}^{-1}$. Weaker perturbations are identified as cloud clusters. However, it should be noted that, due to 
the spatial scale of $\mathrm{TC}$ seeds and the role of atmospheric convection in them, their simulation and sensitivity in GCMs may show model dependence arising from the effective resolution of a model's dynamical core and the model's physical parameterizations (Zhao et al. 2012). Developed based on HiFLOR TCs at the genesis stage using regression-based techniques, PepC does not explicitly model TC seeds or their transition to TCs. KE08 use a seeding rate that varies only with the absolute vorticity near the equator, but their seeds are much weaker than the seeds defined by Hsieh et al. (2020) and the transition of the KE08 seeds to an intensity commensurate with the Hsieh et al. (2020) seeds displays considerable climate sensitivity. Research on the evolution of weak disturbances into TCs is an increasingly active endeavor in tropical meteorology.

\section{Conclusions}

In this study, we investigated the responses of TCs to climate change by comparing projected TCs downscaled from a highresolution global climate model using statistical and statisticaldeterministic methods with those directly resolved in the climate model under the historical and future projected climates. The HiFLOR model is used to produce the climate projections, which drive the two downscaling frameworks. HiFLOR is able to explicitly simulate TCs that are realistic in a number of aspects, and these HiFLOR-generated TCs are used as a reference in the comparisons. Three 70-yr HiFLOR experiments, which represent the climate during the period of 1986-2005, 2016-35, and 2081-2100 under the RCP4.5 scenario, were performed to explore the effects of climate change. The statistical-deterministic downscaling method, KE08, of Emanuel et al. (2008) and the statistical downscaling method, PepC, of Jing and Lin (2020), were used to generate large samples of synthetic TCs for the North Atlantic basin, given the environmental climate change conditions as obtained from the HiFLOR projections.

We find that HiFLOR and, to lesser extent, KE08 simulate significantly more Atlantic TCs by the end of the twenty-first century, although the increases are not significant in the midtwenty-first century, while PepC shows no significant change in TC frequency over the century. All simulation methods project significant increases in the frequency of both major hurricanes and category- 5 hurricanes by the end of the twenty-first century. The fraction of RI storms is also projected to increase significantly, which is consistent with previous studies (e.g., Emanuel 2017; Bhatia et al. 2018). The projected significant increase of RI storms is also consistent with the physical understanding that the rate of intensification scales with the square of the potential intensity (Emanuel 2012). The increase in the fraction of the most intense storms leads to a shift to higher intensity values of the entire LMI distribution under the warmer climate, with HiFLOR responding the most to climate change and PepC the least. This difference in the extent of responses of HiFLOR, KE08, and PepC results in very different tails of the LMI distributions under the future climate although the tails for the three datasets are very similar under the control climate. Nevertheless, the overall increases in TC frequency and especially intensity under the warmer climate do not carry over to landfalling TCs in all of the simulations. The return levels of landfall intensity for the North Atlantic coastline remain nearly the same for future projected conditions as for the control condition. However, minor changes exist at regional scales. HiFLOR projects that the northeastern United States, which has the lowest TC threat, may see a moderate growth of the TC threat as the climate gets warmer. In contrast, in Mexico, the landfalling TC threat may even slightly decrease under a warmer climate according to HiFLOR projections. These regional trends do not exist in KE08 or PepC.

In this study, we examined the performance of a newly developed statistical downscaling approach, PepC, to TC climate change studies, in comparison with dynamic (HiFLOR) and statistical-deterministic downscaling (KE08) methods. We compare findings in this study with previous projections and point out that the large increment of TC frequency in HiFLOR (+22\%) under the RCP4.5 emission scenario is barely seen in previous studies based on CMIP3 and CMIP5 models. The moderate increase in $\mathrm{KE} 08(+8.5 \%)$ and the insignificant change in PepC $(+2.2 \%)$ are closer to previous projections, although those projections were based in many cases on lower-resolution models than HiFLOR. The increase in the overall fraction of category-45 hurricanes projected by HiFLOR $(+126 \%)$ is also much larger than that projected by KE08 (+46\%), PepC (+45\%), and previous studies. As all three simulations are based on the same climate projection, the results indicate that the storm activity in HiFLOR is more sensitive to climate change effects. On the other hand, statistical downscaling models may be less sensitive to climate change effects. More work is needed to further investigate potentials and limitations in TC statistical downscaling methods; possible future work includes a downscaling study for other stateof-the-art climate models, such as CMIP6 climate models. This study focuses on the uncertainty in TC modeling; for future TC projections and applications in decision making, the uncertainty in future climate projections of large-scale environmental conditions (e.g., based on analyzing a range of CMIP6 models under various emission scenarios) should also be considered.

Acknowledgments. This work is supported by National Science Foundation (Grants 1520683 and 1652448).

Data availability statement. The generated statistical synthetic storm datasets are deposited to the NSF DesignSafe-CI and can be accessed online (https://www.designsafe-ci.org/data/browser/ public/designsafe.storage.published/PRJ-3306).

\section{REFERENCES}

Bengtsson, L., K. I. Hodges, M. Esch, N. Keenlyside, L. Kornblueh, J.-J. Luo, and T. Yamagata, 2007: How may tropical cyclones change in a warmer climate? Tellus, 59A, 539-561, https:// doi.org/10.1111/j.1600-0870.2007.00251.x.

Benjamini, Y., and D. Yekutieli, 2001: The control of the false discovery rate in multiple testing under dependency. Ann. Stat., 29, 1165-1188, https://doi.org/10.1214/aos/1013699998.

- and - 2005: False discovery rate adjusted multiple confidence intervals for selected parameters. J. Amer. Stat. Assoc., 100, 71-81, https://doi.org/10.1198/016214504000001907.

Bhatia, K., G. Vecchi, H. Murakami, S. Underwood, and J. Kossin, 2018: Projected response of tropical cyclone intensity and intensification 
in a global climate model. J. Climate, 31, 8281-8303, https://doi.org/ 10.1175/JCLI-D-17-0898.1.

— , G. A. Vecchi, T. Knutson, H. Murakami, J. Kossin, K. Dixon, and C. Whitlock, 2019: Recent increase in tropical cyclone intensification rates. Nat. Commun., 10, 635, https://doi.org/ 10.1038/s41467-019-08471-z.

Bister, M., and K. A. Emanuel, 1998: Dissipative heating and hurricane intensity. Meteor. Atmos. Phys., 65, 233-240, https:// doi.org/10.1007/BF01030791.

—_, and —_, 2002: Low frequency variability of tropical cyclone potential intensity 1 . Interannual to interdecadal variability. J. Geophys. Res., 107, 4801, https://doi.org/10.1029/ 2001JD000776.

Davis, C. A., 2018: Resolving tropical cyclone intensity in models. Geophys. Res. Lett., 45, 2082-2087, https://doi.org/10.1002/ 2017GL076966.

Emanuel, K. A., 1995: Sensitivity of tropical cyclones to surface exchange coefficients and a revised steady-state model incorporating eye dynamics. J. Atmos. Sci., 52, 3969-3976, https://doi.org/10.1175/1520-0469(1995)052<3969:SOTCTS> 2.0.CO;2.

_ 2012: Self-stratification of tropical cyclone outflow: Part II: Implications for storm intensification. J. Atmos. Sci., 69, 988996, https://doi.org/10.1175/JAS-D-11-0177.1.

_ 2013: Downscaling CMIP5 climate models shows increased tropical cyclone activity over the 21st century. Proc. Natl. Acad. Sci. USA, 110, 12 219-12 224, https://doi.org/10.1073/ pnas.1301293110.

__ 2017: Will global warming make hurricane forecasting more difficult? Bull. Amer. Meteor. Soc., 98, 495-501, https://doi.org/ 10.1175/BAMS-D-16-0134.1.

- - , and D. S. Nolan, 2004: Tropical cyclone activity and the global climate system. 26th Conf. on Hurricanes and Tropical Meteorology, Miami, FL, Amer. Meteor. Soc., 240-241, https:// ams.confex.com/ams/26HURR/webprogram/Paper75463.html.

— , S. Ravela, E. Vivant, and C. Risi, 2006: A statistical deterministic approach to hurricane risk assessment. Bull. Amer. Meteor. Soc., 87, 299-314, https://doi.org/10.1175/BAMS-873-299.

_ and global warming: Results from downscaling IPCC AR4 simulations. Bull. Amer. Meteor. Soc., 89, 347-368, https:// doi.org/10.1175/BAMS-89-3-347.

— , K. Oouchi, M. Satoh, T. Hirofumi, and Y. Yamada, 2010: Comparison of explicitly simulated and downscaled tropical cyclone activity in a high-resolution global climate model. J. Adv. Model. Earth Syst., 2 (9), https://doi.org/10.3894/ JAMES.2010.2.9.

Fedorov, A. V., L. Muir, W. R. Boos, and J. Studholme, 2018: Tropical cyclogenesis in warm climates simulated by a cloudsystem resolving model. Climate Dyn., 52, 107-127, https:// doi.org/10.1007/s00382-018-4134-2.

Garner, A. J., and Coauthors, 2017: Impact of climate change on New York City's coastal flood hazard: Increasing flood heights from the preindustrial to 2300 CE. Proc. Natl. Acad. Sci. USA, 114, 11 861-11 866, https://doi.org/10.1073/ pnas. 1703568114.

Harris, L. M., S.-J. Lin, and C. Tu, 2016: High-resolution climate simulations using GFDL HiRAM with a stretched global grid. J. Climate, 29, 4293-4314, https://doi.org/10.1175/JCLI-D-150389.1.

Held, I. M., and M. Zhao, 2011: The response of tropical cyclone statistics to an increase in $\mathrm{CO}_{2}$ with fixed sea surface temperatures. J. Climate, 24, 5353-5364, https://doi.org/ 10.1175/JCLI-D-11-00050.1.

Hsieh, T. L., G. A. Vecchi, W. Yang, I. M. Held, and S. T. Garner, 2020: Large-scale control on the frequency of tropical cyclones and seeds: A consistent relationship across a hierarchy of global atmospheric models. Climate Dyn., 55, 3177-3196, https://doi.org/10.1007/s00382-020-05446-5.

IPCC, 2013: Climate Change 2013: The Physical Science Basis. T. F. Stocker et al., Eds., Cambridge University Press, $1535 \mathrm{pp}$.

Jing, R., and N. Lin, 2019: Tropical cyclone intensity evolution modeled as a dependent hidden Markov process. J. Climate, 32, 7837-7855, https://doi.org/10.1175/JCLI-D-19-0027.1.

— , and —, 2020: An environment-dependent probabilistic tropical cyclone model. J. Adv. Model. Earth Syst., 12, e2019MS001975, https://doi.org/10.1029/2019MS001975.

Kaplan, J., and DeMaria, M., 1995: A simple empirical model for predicting the decay of tropical cyclone winds after landfall. J. Appl. Meteor., 34, 2499-2512, https://doi.org/10.1175/15200450(1995)034<2499:ASEMFP>2.0.CO;2.

Knapp, K. R., M. C. Kruk, D. H. Levinson, H. J. Diamond, and C. J. Neumann, 2010: The International Best Track Archive for Climate Stewardship (IBTrACS): Unifying tropical cyclone data. Bull. Amer. Meteor. Soc., 91, 363-376, https://doi.org/ 10.1175/2009BAMS2755.1.

Knutson, T. R., and R. E. Tuleya, 2004: Impact of $\mathrm{CO}_{2}$-induced warming on simulated hurricane intensity and precipitation: Sensitivity to the choice of climate model and convective parameterization. J. Climate, 17, 3477-3495, https://doi.org/ 10.1175/1520-0442(2004)017<3477:IOCWOS>2.0.CO;2.

,-- , and Y. Kurihara, 1998: Simulated increase of hurricane intensities in a $\mathrm{CO}_{2}$-warmed climate. Science, 279, 1018-1021, https://doi.org/10.1126/science.279.5353.1018.

_ J. J. Sirutis, S. T. Garner, G. A. Vecchi, and I. M. Held, 2008: Simulated reduction in Atlantic hurricane frequency under twenty-first-century warming conditions. Nat. Geosci., 1, 359364, https://doi.org/10.1038/ngeo202.

— Nat. Geosci., 3, 157-163, https://doi.org/10.1038/ngeo779.

— twenty-first-century Atlantic hurricane activity: CMIP3 and CMIP5 model-based scenario. J. Climate, 26, 6591-6617, https://doi.org/10.1175/JCLI-D-12-00539.1.

_ J. J. Sirutis, M. Zhao, R. E. Tuleya, M. Bender, G. A. Vecchi, G. Villarini, and D. Chavas, 2015: Global projections of intense tropical cyclone activity for the late twenty-first century from dynamical downscaling of CMIP5/RCP4.5 scenarios. J. Climate, 28, 7203-7224, https://doi.org/10.1175/JCLI-D-150129.1.

- and Coauthors, 2020: Tropical cyclones and climate change assessment: Part II: Projected response to anthropogenic warming. Bull. Amer. Meteor. Soc., 101, E303-E322, https:// doi.org/10.1175/BAMS-D-18-0194.1.

Korty, R. L., K. A. Emanuel, M. Huber, and R. A. Zamora, 2017: Tropical cyclones downscaled from simulations with very high carbon dioxide levels. J. Climate, 30, 649-667, https://doi.org/ 10.1175/JCLI-D-16-0256.1.

Kossin, J. P., T. L. Olander, and K. R. Knapp, 2013: Trend analysis with a new global record of tropical cyclone intensity. J. Climate, 26, 9960-9976, https://doi.org/10.1175/JCLID-13-00262.1.

Lee, C.-Y., M. K. Tippett, S. J. Camargo, and A. H. Sobel, 2015: Probabilistic multiple linear regression modeling for tropical 
cyclone intensity. Mon. Wea. Rev., 143, 933-954, https:// doi.org/10.1175/MWR-D-14-00171.1.

$\longrightarrow,-$ A. H. Sobel, and S. J. Camargo, 2016: Autoregressive modeling for tropical cyclone intensity climatology. J. Climate, 29, 7815-7830, https://doi.org/10.1175/JCLI-D-15-0909.1.

,,--- , and — , 2018: An environmentally forced tropical cyclone hazard model. J. Adv. Model. Earth Syst., 10, 223-241, https://doi.org/10.1002/2017MS001186.

—, S. J. Camargo, A. H. Sobel, and M. K. Tippett, 2020: Statistical-dynamical downscaling projections of tropical cyclone activity in a warming climate: Two diverging genesis scenarios. J. Climate, 33, 4815-4834, https://doi.org/10.1175/ JCLI-D-19-0452.1.

Li, T., M. Kwon, M. Zhao, J.-S. Kug, J.-J. Luo, and W. Yu, 2010: Global warming shifts Pacific tropical cyclone location. Geophys. Res. Lett., 37, L21804, https://doi.org/10.1029/2010GL045124.

Lin, N., and K. Emanuel, 2016: Grey swan tropical cyclones. Nat. Climate Change, 6, 106-111, https://doi.org/10.1038/ nclimate2777.

Liu, M., G. A. Vecchi, J. A. Smith, and T. R. Knutson, 2019: Causes of large projected increases in hurricane precipitation rates with global warming. npj Climate Atmos. Sci., 2, 38, https:// doi.org/10.1038/s41612-019-0095-3.

Manganello, J. V., and Coauthors, 2014: Future changes in the western North Pacific tropical cyclone activity projected by a multidecadal simulation with a 16-km global atmospheric GCM. J. Climate, 27, 7622-7646, https://doi.org/10.1175/JCLID-13-00678.1.

Marsooli, R., N. Lin, K. Emanuel, and K. Feng, 2019: Climate change exacerbates hurricane flood hazards along US Atlantic and Gulf Coasts in spatially varying patterns. Nat. Commun., 10, 3785, https://doi.org/10.1038/s41467-019-11755-z.

Mendelsohn, R., K. Emanuel, S. Chonabayashi, and L. Bakkensen, 2012: The impact of climate change on global tropical cyclone damage. Nat. Climate Change, 2, 205-209, https://doi.org/ 10.1038/nclimate1357.

Murakami, H., and Coauthors, 2012: Future changes in tropical cyclone activity projected by the new high-resolution MRIAGCM. J. Climate, 25, 3237-3260, https://doi.org/10.1175/ JCLI-D-11-00415.1.

— and 5 hurricanes in the high-resolution GFDL HiFLOR coupled climate model. J. Climate, 28, 9058-9079, https://doi.org/ 10.1175/JCLI-D-15-0216.1.

_ , and Coauthors, 2016: Seasonal forecasts of major hurricanes and landfalling tropical cyclones using a high-resolution GFDL coupled climate model. J. Climate, 29, 7977-7989, https://doi.org/10.1175/JCLI-D-16-0233.1.

Rayner, N. A., D. E. Parker, E. B. Horton, C. K. Folland, L. V. Alexander, D. P. Rowell, E. C. Kent, and A. Kaplan, 2003: Global analyses of sea surface temperature, sea ice, and night marine air temperature since the late nineteenth century. J. Geophys. Res., 108, 4407, https://doi.org/10.1029/2002JD002670.

Schade, L. R., and K. A. Emanuel, 1999: The ocean's effect on the intensity of tropical cyclones: Results from a simple coupled atmosphere-ocean model. J. Atmos. Sci., 56, 642-651, https://doi.org/10.1175/1520-0469(1999)056<0642:TOSEOT> 2.0.CO;2.

Scoccimarro, E., S. Gualdi, G. Villarini, G. A. Vecchi, M. Zhao, K. Walsh, and A. Navarra, 2014: Intense precipitation events associated with landfalling tropical cyclones in response to a warmer climate and increased $\mathrm{CO}_{2}$. J. Climate, 27, 4642-4654, https://doi.org/10.1175/JCLI-D-14-00065.1.
, P. G. Fogli, K. A. Reed, S. Gualdi, S. Masina, and A. Navarra, 2017: Tropical cyclone interaction with the ocean: The role of high-frequency (subdaily) coupled processes. J. Climate, 30, 145-162, https://doi.org/10.1175/JCLI-D-16-0292.1.

Small, R. J., and Coauthors, 2014: A new synoptic scale resolving global climate simulation using the Community Earth System Model. J. Adv. Model. Earth Syst., 6, 1065-1094, https:// doi.org/10.1002/2014MS000363.

Stansfield, A. M., K. A. Reed, and C. M. Zarzycki, 2020: Changes in precipitation from North Atlantic tropical cyclones under RCP scenarios in the variable-resolution Community Atmosphere Model. Geophys. Res. Lett., 47, e2019GL086930, https://doi.org/ 10.1029/2019GL086930.

Sugi, M., A. Noda, and N. Sato, 2002: Influence of the global warming on tropical cyclone climatology: An experiment with the JMA global climate model. Meteor. Soc. Japan, 80, 249272, https://doi.org/10.2151/jmsj.80.249.

_, Y. Yamada, K. Yoshida, R. Mizuta, M. Nakano, C. Kodama, and M. Satoh, 2020: Future changes in the global frequency of tropical cyclone seeds. SOLA, 16, 70-74, https://doi.org/ 10.2151/sola.2020-012.

Tippett, M. K., S. J. Camargo, and A. H. Sobel, 2011: A Poisson regression index for tropical cyclone genesis and the role of large-scale vorticity in genesis. J. Climate, 24, 2335-2357, https://doi.org/10.1175/2010JCLI3811.1.

Tory, K. J., S. S. Chand, J. L. McBride, H. Ye, and R. A. Dare, 2013: Projected changes in late-twenty-first-century tropical cyclone frequency in 13 coupled climate models from phase 5 of the Coupled Model Intercomparison Project. J. Climate, 26, 99469959, https://doi.org/10.1175/JCLI-D-13-00010.1.

van der Wiel, K., S. B. Kapnick, and G. A. Vecchi, 2017: Shifting patterns of mild weather in response to projected radiative forcing. Climatic Change, 140, 649-658, https://doi.org/10.1007/ s10584-016-1885-9.

van Vuuren, D. P., and Coauthors, 2011: The representative concentration pathways: An overview. Climatic Change, 109, 531, https://doi.org/10.1007/s10584-011-0148-z.

Vecchi, G. A., and Coauthors, 2019: Tropical cyclone sensitivities to $\mathrm{CO}_{2}$ doubling: Roles of atmospheric resolution, synoptic variability, and background climate changes. Climate Dyn., 53, 5999-6033, https://doi.org/10.1007/s00382-019-04913-y.

Viale, F., and T. M. Merlis, 2017: Variations in tropical cyclone frequency response to solar and $\mathrm{CO}_{2}$ forcing in aquaplanet simulations. J. Adv. Model. Earth Syst., 9, 4-18, https://doi.org/ 10.1002/2016MS000785.

Vickery, P. J., P. F. Skerlj, and L. A. Twisdale, 2000: Simulation of hurricane risk in the U.S. using empirical track model. J. Struct. Eng., 126, 1222-1237, https://doi.org/10.1061/(ASCE) 0733-9445(2000)126:10(1222).

Vidale, P. L., and Coauthors, 2021: Impact of stochastic physics and model resolution on the simulation of tropical cyclones in climate GCMs. J. Climate, 34, 4315-4341, https://doi.org/ 10.1175/JCLI-D-20-0507.1.

Villarini, G., and G. Vecchi, 2012: Twenty-first-century projections of North Atlantic tropical storms from CMIP5 models. Nat. Climate Change, 2, 604-607, https://doi.org/10.1038/nclimate1530.

Walsh, K. J., and Coauthors, 2016: Tropical cyclones and climate change. Wiley Interdiscip. Rev.: Climate Change, 7, 65-89, https://doi.org/10.1002/wcc.371.

Wehner, M. F., and Coauthors, 2014: The effect of horizontal resolution on simulation quality in the Community Atmospheric Model, CAM 5.1. J. Adv. Model. Earth Syst., 6, 980-997, https:// doi.org/10.1002/2013MS000276. 
Wilks, D. S., 2011: Statistical Methods in the Atmospheric Sciences. 3rd ed. International Geophysics Series, Vol. 100, Academic Press, $676 \mathrm{pp}$.

Yamada, Y., M. Satoh, M. Sugi, C. Kodama, A. T. Noda, M. Nakano, and T. Nasuno, 2017: Response of tropical cyclone activity and structure to global warming in a high-resolution global nonhydrostatic model. J. Climate, 30, 9703-9724, https://doi.org/ 10.1175/JCLI-D-17-0068.1.

_ , and Coauthors, 2021: Evaluation of the contribution of tropical cyclone seeds to changes in tropical cyclone frequency due to global warming in high-resolution multi-model ensemble simulations. Prog. Earth Planet. Sci., 8, 11, https:// doi.org/10.1186/s40645-020-00397-1.
Yeo, D., N. Lin, and E. Simiu, 2014: Estimation of hurricane wind speed probabilities: Application to New York City and other coastal locations. J. Struct. Eng., 140, 04014017, https://doi.org/ 10.1061/(ASCE)ST.1943-541X.0000892.

Zhang, W., and Coauthors, 2016: Improved simulation of tropical cyclone responses to ENSO in the western North Pacific in the high-resolution GFDL HiFLOR coupled climate model. J. Climate, 29, 1391-1415, https://doi.org/10.1175/JCLI-D15-0475.1.

Zhao, M., I. M. Held, and S.-J. Lin, 2012: Some counter-intuitive dependencies of tropical cyclone frequency on parameters in a GCM. J. Atmos. Sci., 69, 2272-2283, https://doi.org/10.1175/ JAS-D-11-0238.1. 